\title{
ХРОМАТОГРАФИЯ В СУХОЙ КОЛОНКЕ. СОСТАВ СМОЛЫ ПОЛУКОКСОВАНИЯ ЛИПТОБИОЛИТА
}

Хроматография в сухой колонке (dry column chromatography) является аналогом препаративной тонкослойной хроматографии, но позволяет разделить бо́льшее количество исследуемых веществ. Если на тонкослойной хроматографии (ТСX) навески пробы - порядка 0,5 , то для сухой колонки количество пробы - около 5 г. Сущность метода сухой колонки состоит в том, что шихта адсорбента в колонке только заполняется элюирующим растворителем, проходящим через слой адсорбента с исследуемым веществом (через старт). Хроматографирование заканчивают за несколько миллиметров до достижения фронтом элюента конца шихты. Таким образом, элюент из адсорбента не выходит, в колонке остается и исследуемое вещество, распределенное элюентом теперь уже по всей длине колонки в зависимости от полярности отдельных компонентов исследуемой смеси. После хроматографирования адсорбент с веществом извлекают по зонам из колонки и после испарения элюента адсорбированные фракции выделяют экстракцией подходящим растворителем.

Первый вариант метода сухой колонки (нисходящий элюирующий поток) был разработан в 1965 году ['], и вскоре он нашел широкое применение в биохимических исследованиях для разделения липидов, алкалоидов и т. д. $\left.{ }^{2-4}\right]$. Стали применять и способ восходящим потоком элюента с использованием небольшого вакуума $\left[{ }^{5,6}\right]$.

\section{Экспериментальная часть}

При разработке метода сухой колонки для исследования состава жидких продуктов переработки твердых топлив в основу взяли разработанный для группового анализа тех же продуктов вариант препаратив-

Таблица 1

Хроматографические методы препаративного разделения жидких продуктов переработки твердых топлив

\begin{tabular}{|c|c|c|}
\hline Показатели & $\begin{array}{l}\text { Тонкослойная } \\
\text { хроматография }\end{array}$ & $\begin{array}{c}\text { Сухая } \\
\text { колонка }\end{array}$ \\
\hline $\begin{array}{l}\text { Навеска пробы, г } \\
\text { Весовое отношение проба/абсорбент (сред- } \\
\text { нее) } \\
\text { Длина пробега элюента, см } \\
\text { Время элюирования, ч } \\
\text { Температура элюнрования, }{ }^{\circ} \mathrm{C} \\
\text { Выход, \% }\end{array}$ & $\begin{array}{l}\text { до } 0,5 \\
1: 150 \\
20 \\
0,75-1,25 \\
+20 \\
90-96\end{array}$ & $\begin{array}{c}\text { до } 5 \\
1: 50 \\
50 \\
6-9 \\
+1-+5 \\
94-98\end{array}$ \\
\hline
\end{tabular}



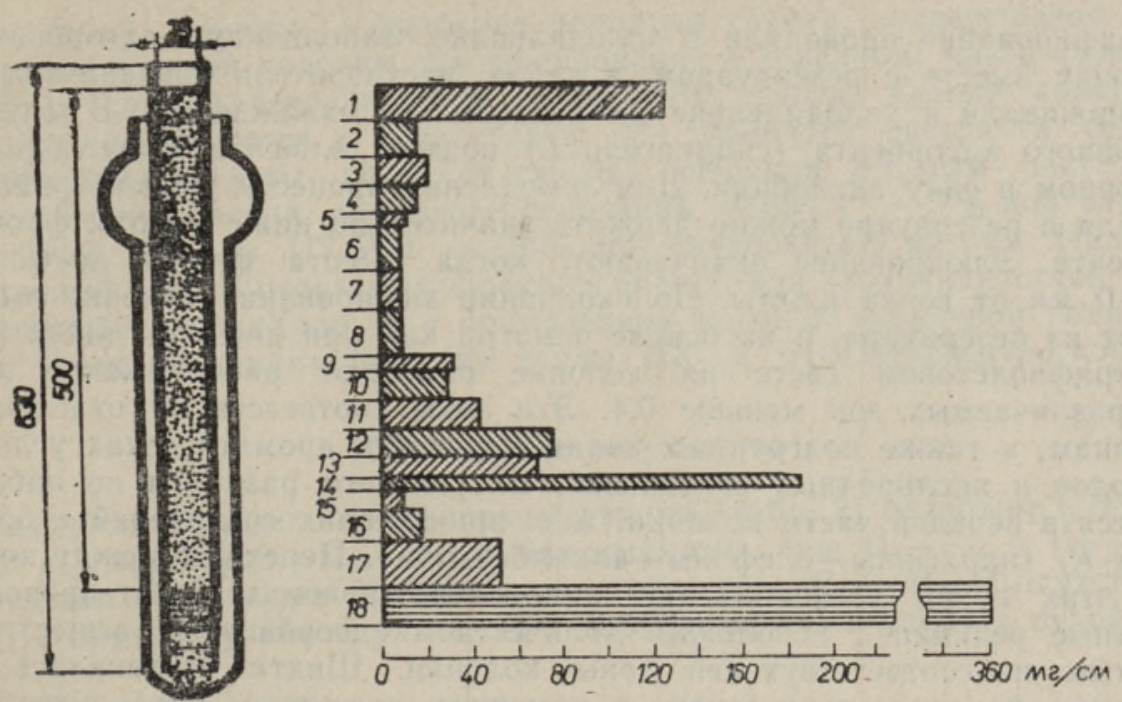

Рнс. 1. Слева: схематическое изображение сухой колонки. Справа: расположение зон и концентрация веществ в зонах после хроматографирования смолы рабдописсита; номера зон $(1-18)$ соответствуют фракциям (подгруппам) в табл. 2.

ной TCX [ $\left.{ }^{7}\right]$. Адсорбентом служил силикагель $L$ (Chemapol) с величиной зерен 40-100 или 100-160 мкм. Применяли и другие адсорбенты. В качестве растворителя-элюента использовали н-гексан. Для исследования была взята смола полукоксования дальневосточного липтобиолита (рабдописсита) верхне-суйфунского месторождения. Выход смолы полукоксования - $35 \%$ на органическое вещество, содержание фенолов в смоле $-24,9 \%$.

Хроматографирование проводилось в режиме восходящего потока, причем аппаратурное оформление было предельно простым аналогично [8]. Некоторые характеристики метода представлены в табл. 1. Колонка - стеклянная трубка длиной 63 см, с внутренним диаметром 2,5 см. Для загрузки такой колонки требуется 180-190 г силикагеля. Использованный рабочий слой шихты, представляющий собой длину разделения, в такой колонке - 50 cм. Стеклянный резервуар для элюента, по существу, большая пробирка, внутренний диаметр резервуара на 3-4 мм больше внешнего диаметра колонки. Для размещения всего нужного количества растворителя к верхней части резервуара была припаяна расширенная часть (рис. 1). Расход растворителя - около 250 мл.

В большинстве случаев адсорбент загружали в колонку в сухом виде $\left[{ }^{8}\right]$, т. е. пробу в колонку на шихту (колонка заполняется в перевернутом виде) наносили вместе с адсорбентом, что обеспечило равномерное распределение исследуемого вещества на старте. Для этого проба смешивалась с адсорбентом до рассыпчатого состояния этой смеси; количество силикагеля 6-12 г. Маловязкие жидкие пробы можно наносить на шихту по каплям, распределяя равномерно по поверхности шихты адсорбента. В обоих случаях на слой пробы (старт) наносили еще слой чистого адсорбента (1,5-2 см). Конец колонки плотно затыкали гидроскопической ватой. Для предотвращения изоме. ризации олефинов и полимеризации нестабильных соединений хрома- 
тографирование проводили в холодильнике. Заполненную адсорбентом колонку вместе с резервуаром, а также растворитель предварительно выдерживали в холодильнике до полного их охлаждения. В случае активного адсорбента (силикагель $L$ ) подъем элюента происходит в основном в силу адсорбции. Для замедления процесса уровень растворителя в резервуаре можно держать значительно ниже высоты фронта элюента. Элюирование оканчивают, когда высота фронта достигнет 5-10 мм от верха шихты. По окончании элюирования колонку вынимают из резервуара, и на основе осмотра как при дневном, так и при ультрафиолетовом свете на колонке отмечают расположение зон. $R_{f}$ различаемых зон меньше 0,4 . Эти зоны соответствуют отдельным группам, а также подгруппам полициклических ароматических углеводородов и кислородных соединений. Визуального различия не наблюдается в верхней части колонки, т. е. при группах соединений с бо́льшим $R_{f}$ (парафины-олефины-алкилбензолы). Переходы между зонами этих групп устанавливают аналогично приемам ТСX: проводят цветные реакции с небольшим количеством адсорбента с веществом, взятым из соответствующей зоны колонки. Шихта извлекалась из колонки по отдельным зонам с помощью согнутого металлического шпателя. Вещество экстрагировали эфиром на стеклянном фильтре. Эфир отгоняли на водяной бане с применением дефлегматора.

Данные разделения смолы полукоксования липтобиолита в сухой колонке и на пластинке ТСХ приведены в табл. 2. Распределение соединений в сухой колонке такое же, как и на пластинке ТСX с двуили трехкратным элюированием пластинки тем же растворителем

таблица 2

Разделение смолы полукоксования рабдописсита

\begin{tabular}{|c|c|c|c|c|c|c|c|}
\hline \multirow{3}{*}{ 吾 } & \multirow{3}{*}{ Соединения } & \multicolumn{4}{|c|}{ Сухая колонка } & \multirow{2}{*}{\multicolumn{2}{|c|}{$\begin{array}{c}\begin{array}{c}\text { Тонкослойная } \\
\text { хроматография }\end{array} \\
\text { группы } \\
\end{array}$}} \\
\hline & & \multicolumn{2}{|c|}{ подгруппы } & \multicolumn{2}{|c|}{ группы } & & \\
\hline & & $R_{f}^{*}$ & $\%$ & $R_{f}^{*}$ & $\%$ & $R_{f}^{*}$ & $\%$ \\
\hline $\begin{array}{l}1 \\
2 \\
3 \\
4 \\
5\end{array}$ & $\begin{array}{c}\text { Алканы } \\
\text { Алкены } \\
\text {," } \\
, "\end{array}$ & $\begin{array}{l}1,0 \\
0,93 \\
0,87 \\
0,80 \\
0,74\end{array}$ & $\begin{array}{r}13,1 \\
1,6 \\
2,1 \\
1,6 \\
0,3\end{array}$ & 1,0 & 18,7 & 1,0 & 16,6 \\
\hline $\begin{array}{r}6 \\
7 \\
8 \\
9 \\
10\end{array}$ & $\begin{array}{c}\text { Алкилбензолы } \\
\text { " } \\
\text { " }\end{array}$ & $\begin{array}{l}0,72 \\
0,64 \\
0,55 \\
0,46 \\
0,44\end{array}$ & $\begin{array}{l}1,2 \\
1,3 \\
1,1 \\
1,1 \\
2,4\end{array}$ & 0,72 & 7,1 & 0,56 & 5,1 \\
\hline $\begin{array}{l}11 \\
12 \\
13\end{array}$ & $\begin{array}{c}\text { Полициклическая } \\
\text { ароматнка } \\
\text {, } \\
\text {, }\end{array}$ & $\begin{array}{l}0,39 \\
0,32 \\
0,27\end{array}$ & $\begin{array}{l}4,3 \\
6,4 \\
4,6\end{array}$ & 0,39 & 15,3 & 0,34 & 14,5 \\
\hline $\begin{array}{l}15 \\
16\end{array}$ & $\begin{array}{l}\text { Кислородные } \\
\text { соединения } \\
\text {, } \\
,\end{array}$ & $\begin{array}{l}0,23 \\
0,20 \\
0,16\end{array}$ & $\begin{array}{l}8,4 \\
0,5 \\
1,6\end{array}$ & 0,23 & 10,5 & 0,16 & 19,3 \\
\hline 17 & Фенолы & 0,09 & 8,0 & 0,09 & 8,0 & & \\
\hline 18 & Старт & 0 & 38,8 & 0 & 38,8 & 0 & 37,9 \\
\hline & Выход & & 98,4 & & 98,4 & & 93,4 \\
\hline
\end{tabular}

* $R_{f}$ - максимальный для данной фракщни. 
(гексаном). Фенолы - наиболее полярная группа, подвергшаяся разделению в сухой колонке при элюировании с гексаном; часть фенолов $(8 \%$ от смолы) передвигается дальше от старта. Самые полярные соединения остаются в зоне старта. Из эфирного экстракта старта карбоновые кислоты $(1,4 \%$ от смолы) извлекли $8 \%$-ным раствором бикарбоната натрия, азотистые основания $(0,65 \%)-7 \%$-ной серной кислотой, фенолы $(17,5 \%)-10 \%$-ной гидроокисью натрия. Индивидуальный состав отдельных фракций определяли газо-жидкостной хроматографией на «Хром-4» с применением колонок различной полярно-

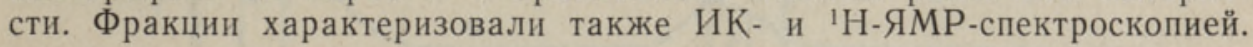

\section{Обсуждение результатов}

Суммарная парафино-олефиновая фракция (табл. 2) содержит в основном $\mu$-углеводороды $\mathrm{C}_{8}-\mathrm{C}_{31}$, с максимумами при $\mathrm{C}_{8}-\mathrm{C}_{10}$ и $\mathrm{C}_{22}-\mathrm{C}_{27}$. Представлены также изопреновые структуры $i \mathrm{C}_{14}-i \mathrm{C}_{19}$ (отсутствует $\left.i \mathrm{C}_{17}\right)$. Внутригрупповое разделение парафинов и олефинов в сухой ко-
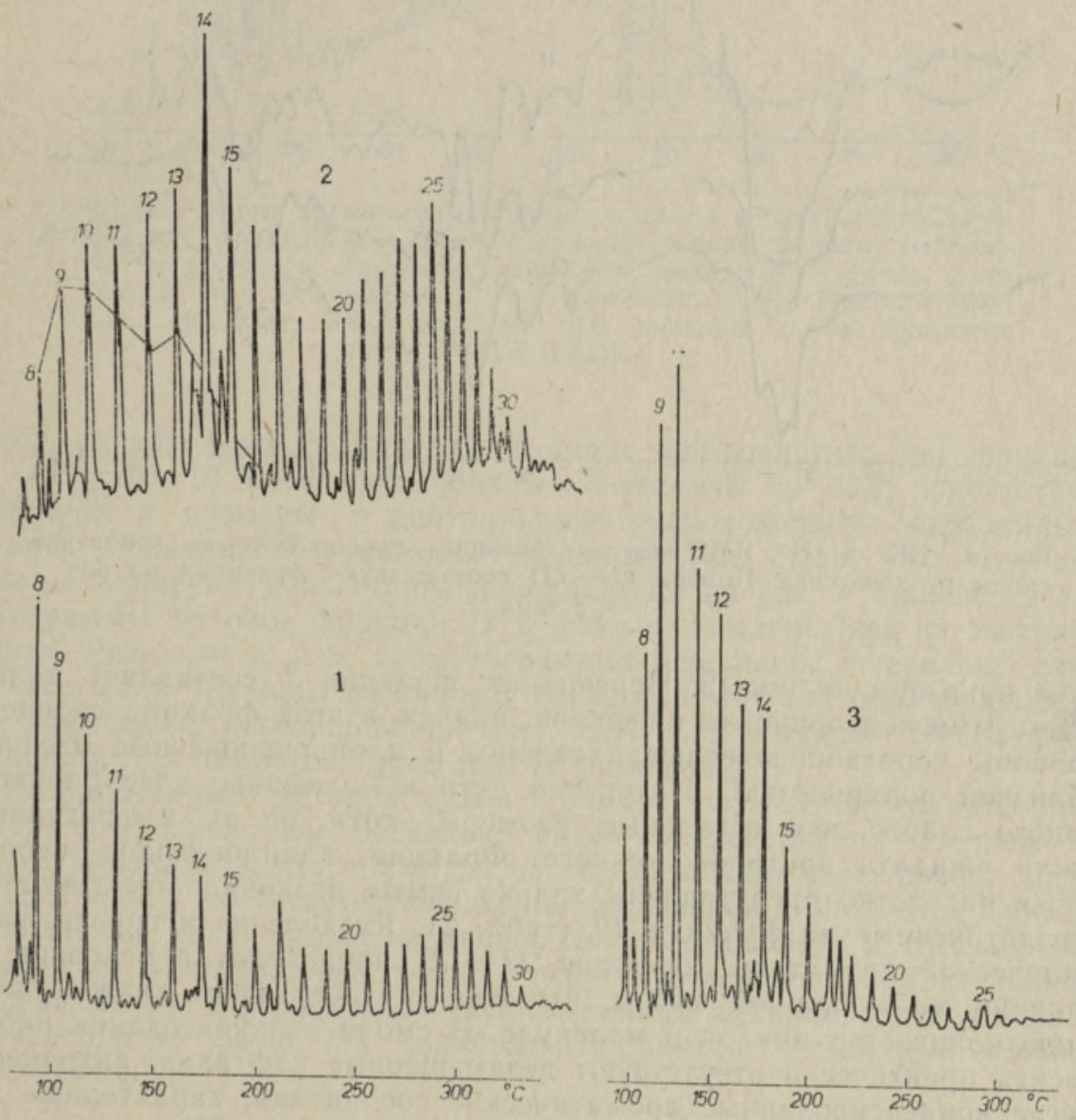

Рис. 2. Газовые хроматограммы первых трех фракций, разделенных хроматографированием в сухой колонке смолы рабдописсита. 1 - алканы, 2 - алканы + алкены, 3 - алкены. Цифры $(8-30)$ указывают число атомов углерода в цепи $н$-алкана нли $н$-алкена-1. На хроматограмме фракций линией соединены пики $н$-алканов. Қолонка $3,6 м \times 3$ мм, $7 \%$ Е301 на целите 545. 


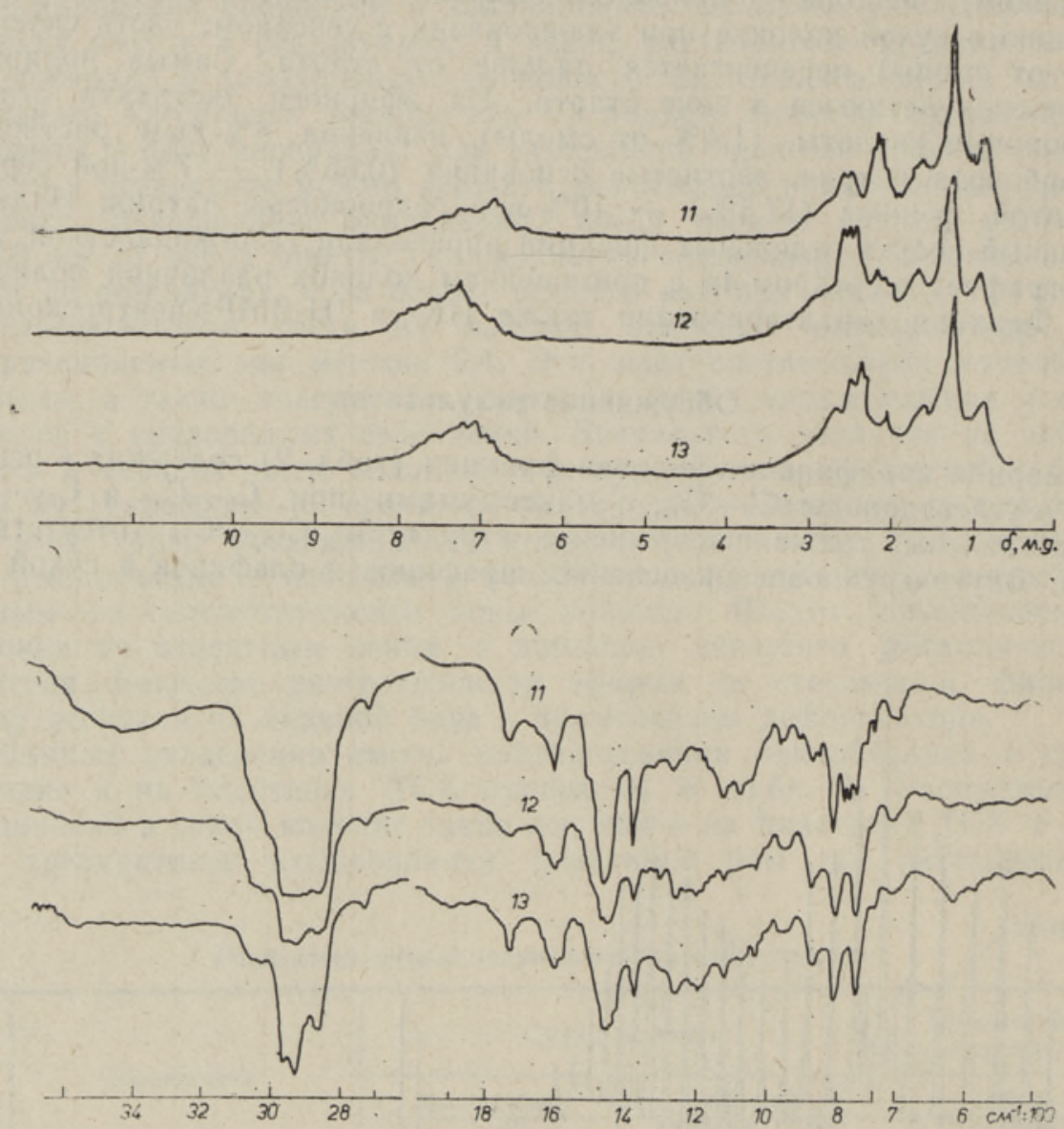

Рис. 3. ИК- и ${ }^{1} \mathrm{H}$ - ЯМР-спектры фракций полициклической ароматики смолы рабдописсита. Номера $(11-13)$ соответствуют фракциям на рис. 1 и в табл. 2.

лонке показано на рис. 2. Переходная фракция 2 составляет только $8,5 \%$ суммы парафинов и олефинов, причем в этой фракции сконцентрированы короткоцепочечные парафины и длинноцепочечные олефины с близкой полярностью. Интересно, что $H$-1-олефины адсорбируются немного слабее, чем остальные изомеры, хотя по их конфигурации можно ожидать противоположного. Фракции алкилбензолов небольшие, в них четко представлены только самые низкокипящие гомологи, сосредоточенные во фракции 10 (табл. 2). Разделение в группе полициклической ароматики (фракции 11-13) происходит в основном по величине молекулярной массы, что соответствует здесь также увеличению количества циклов в молекуле. В смоле полукоксования рабдописсита практически отсутствуют незамещенные нафталин, антрацен и другие конденсированные ароматические соединения, характерные для большинства смол термической переработки топлив. По данным ИКи 'Н-ЯМР-спектров (рис. 3), полициклическая ароматика содержит довольно много алифатических структурных элементов-боковых ответвлений и алициклических структур, т. е. полициклическая ароматика имеет гибридный характер. 


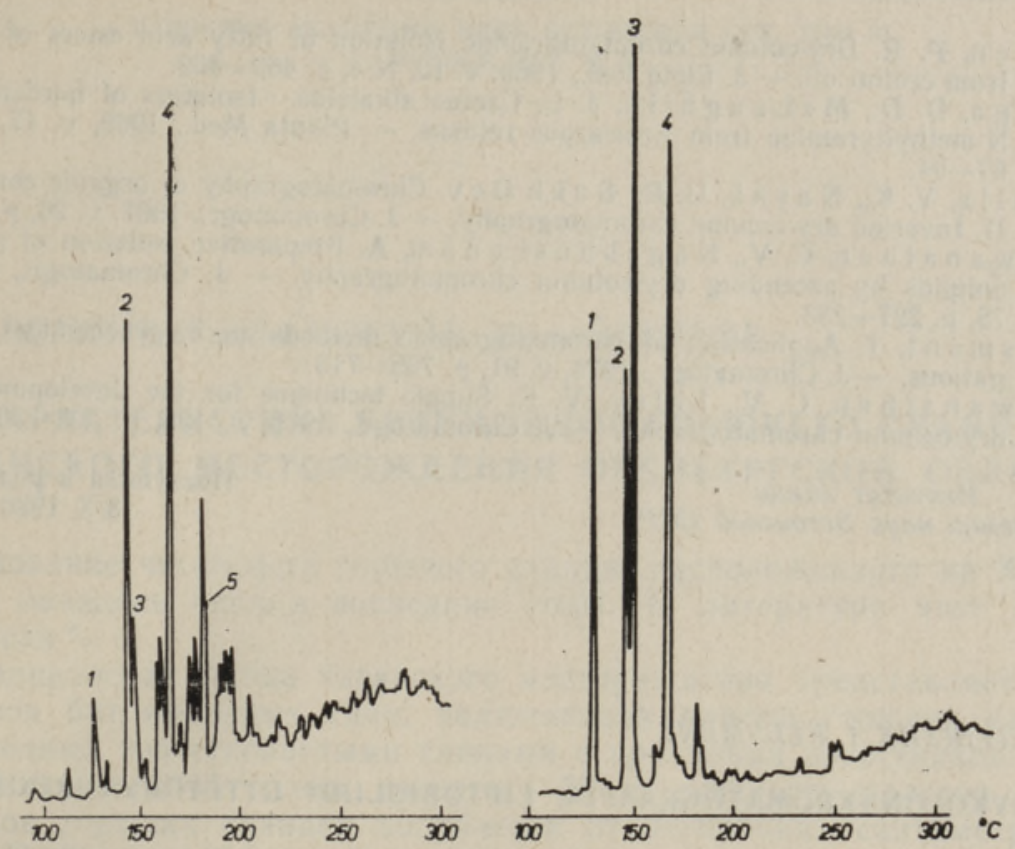

Рис. 4. Газовые хроматопраммы фенолов смолы рабдописсита. Слева: фракция 17, выделенная в сухой колонке; справа: фенолы, выделенные из экстракта стартовой линии. Соединения: 1 - фенол, 2 $o$-крезол, 3 - м- и $n$-крезолы, $4-2,5$-ксиленол, 5 - 3-метил-5-этилфенол. Колонка: $3,6 \mu \times 3$ м. $8 \%$ апиезона $L$ на хроматоне N-AW-HMDS.

Из кислородных соединений в смоле рабдописсита, во фракциях $14-16$ (табл. 2) идентифицированы $\mu$-алканоны $\mathrm{C}_{9}-\mathrm{C}_{19}$, присутствуют 2 -изомеры и изомеры с центральным расположением карбонильной группы. Фракцию 17 составляют фенолы. Как было уже отмечено, фенолы элюируются из старта неполностью: на рис. 4 приведены хроматограммы фенолов фракции 17 и фенолов, выделенных из экстракта старта. Различия в этих хроматограммах небольшие, поскольку длина пробега мала $\left(R_{f}\right.$ зоны фенолов $\left.0-0,09\right)$. Хроматограммы показывают, что вследствие экранирования гидроксильной группы 2-метилфенол адсорбируется немного слабее других изомеров.

Разработанным методом сухой хроматографической колонки были проанализированы еще несколько смол полукоксования сланцев. Результаты показали, что, несмотря на весьма низкое соотношение адсорбента и пробы, достигается разделение парафинов и олефинов, частично разделяются также изомеры кислородных соединений и соединения с различным молекулярным весом. Требует усовершенствования техника эксперимента, например, определение границы алкилбензолы-олефины. Целесообразно было бы использовать вместо стеклянных колонок нейлоновые.

\section{Л ИТЕРА Т У РА}

1. L o e v, B., S n a d e r, K. Dry-column chromatography. A preliminary report. - Chem. Ind. (London), 1965, v. 1, p. 15. (Chem. Abstr. 1965, v. 62, N 8693 b.)

2. C a se y, A. Separation of neutral lipids of shark liver by dry-column chromatography. - J. Lipid Res., 1969, v. 10, N 4, p. 456-459. 
3. O cken, P. R. Dry-column chromatographic isolation of fatty acid esters of phorbol from croton oil, - J. Lipid Res., 1969, v. 10, N 4, p. 460-462.

4. B r a g a, D. D., McLa ug hl i n, J. L. Cactus alkaloids. Isolation of hordenine and N-methyltyramine from Ariocarpus retusus. - Planta Med., 1969, v. 17, N 1, p. $87-94$

5. B hall a, V. K., N a y a k, U. R., S u kh D ev. Chromatography of organic compounds II. Inverted dry-column chromatography. - J. Chromatogr., 1967, v. 26, p. 54-61.

6. Viswan athan, C. V., Nagabhushan am, A. Preparative isolation of phosphonolipids by ascending dry-column chromatography. - J. Chromatogr., 1973, v. 75 , p. $227-233$.

7. Klesment, I. Application of chromatographic methods in biogeochemical investigations. - J. Chromatogr., 1974, v. 91, p. 705-713.

8. Viswanathan, C. V., Leley, V. K. Simple technique for the development of a dry-column chromatography. - J. Chromatogr., 1976, v. 128, p. 302-303.

Институт химии
Академии наук Эстонской ССР

Поступила в редакцию $3 / \mathrm{X} 1980$

Silvia KIVIRÄHK, I. KLESMENT

\title{
KUIVKOLONNKROMATOGRAAFIA. LIPTOBIOLIIDI UTTETORVA KOOSTIS
}

Artiklis esitatud meetod on oma pōhimõttelt lähedane õhukese kihi kromatograafiale, kuid selle abil saab ühendirühmadeks lahutada kuni $5 \mathrm{~g}$ õli. On vōimalik ka rühmasisene jaotus, kusjuures saab eraldada näit. parafiine ja olefiine. Liptobioliidi uttetõrvale on iseloomulikud pika ahelaga parafiinid ja olefiinid, mitmeid kõrvalahelaid ja alitsüklilisi struktuure sisaldavad polütsüklilised aromaatsed süsivesinikud $\mathrm{ja}$ ühealuselised fenoolid.

\author{
Silvia KIVIRAHK, I. KLESMENT
}

\section{DRY COLUMN CHROMATOGRAPHY. THE COMPOSITION OF LIPTOBIOLITH SEMICOKING TAR}

In principle, the method presented by the authors approaches thin-layer chromatography, but with its aid only oil samples not exceeding $5 \mathrm{~g}$ can be separated into compound groups. An intragroup separation is likewise possible, at which, for example, paraffins and olefins can be separated. Characteristic properties of liptobiolith semicoking tar are longchain paraffins and olefins, polycyclic aromatic hydrocarbons containing various side chaias and alicyclic structures, as well as monobasic phenols. 